\title{
BMJ Health \& Care Informatics \\ BMJ HCI launches partnership programme for patients and carers as authors and peer reviewers
}

Dana Lewis (D) , ${ }^{1}$ Philip Scott (D) ${ }^{2}$

To cite: Lewis D, Scott P. $B M J ~ H C l$ launches partnership programme for patients and carers as authors and peer reviewers. BMJ Health Care Inform 2021;28:e100471. doi:10.1136/ bmjhci-2021-100471

Received 27 August 2021 Accepted 17 September 2021
Check for updates

(C) Author(s) (or their employer(s)) 2021. Re-use permitted under CC BY-NC. No commercial re-use. See rights and permissions. Published by BMJ.

${ }^{1}$ OpenAPS, Seattle, Washington, USA

${ }^{2}$ Centre for Healthcare Modelling \& Informatics, University of Portsmouth Faculty of Technology, Portsmouth, UK

Correspondence to

Dana Lewis;

Dana@0penAPS.org

\begin{abstract}
BMJ Health \& Care Informatics (BMJHCl) is launching a partnership programme, where patients write articles and serve as peer reviewers on both patient-written and researcher-written articles. This article outlines the programme and describes the importance of public involvement in research and implementation in digital health. We think patients and carers should be funded to participate at this stage of research as well as other stages of research. The quality of peer review can be greatly improved by recruiting patients to peer review and improve readability and understanding of scientific literature and to ensure that research and other articles appropriately include what matters most to patients. Just as real-time communication is two-way communication, both healthcare providers and patients should have a voice in the literature, and involving patients in journals is an important step toward amplifying and supporting the balance of perspectives. Patients are the whole purpose of research and practice in health and care, so this rightly includes their role in the publication and review of health informatics literature as well as the publication of their own perspectives regarding access and delivery of healthcare. Patients and carers can provide valuable insights into research articles, and they can also serve as effective peer reviewers. The BMJHCl is excited to kick off the new partnership programme and encourages all interested patients and carers to apply to participate as authors and/or reviewers.
\end{abstract}

\section{INTRODUCTION}

BMJ Health $\mathcal{E}$ Care Informatics (BMJHCI) is launching a partnership programme ${ }^{1}$, where patients and carers write articles and serve as peer reviewers on both patient-written and researcher-written articles. This article outlines the programme and describes the importance of public involvement in research and implementation in digital health.

\section{WHAT THE BMJHCI PARTNERSHIP PROGRAMME IS}

First, let us clarify the terminology and scope of the BMJHCI partnership programme. In physiological medical care, the word 'patient' is fairly obvious and typically denotes the 'subject' of clinical diagnosis or treatment.
However, we are also including people who participate in mental health services or social care. Using the term 'patient' in such contexts is viewed as inappropriate in many jurisdictions, and alternative expressions such as 'service user' or 'client' tend to be adopted. We also want to include the general public, whether or not they are currently receiving health or care services, as they ultimately fund these services either through taxation or insurance. The 'public' have legitimate interests not just as funders, but as citizens who want society to be healthy and thriving. Therefore, the scope includes not just care of illness, but promotion of public health and well-being. All of these areas have aspects of digital technology, so our partnership programme is equally broad, and when we say 'patient' or 'public' in this article, we mean it in this globally inclusive sense. That being said, it is often the recipients of care services (and their family, or other informal carers) who can offer the most direct human insights into what works and does not work. We want all of these voices to be heard.

Therefore, to enable more voices to be heard and to enhance the inclusivity and accessibility of our readership, we will invite participants to both peer review submitted papers and sometimes to write an article on a topic selected by the oversight panel and agreed by the editor in this new partnership programme.

\section{HOW THE BMJHCI PARTNERSHIP PROGRAMME WILL WORK, AND HOW TO APPLY}

Participating in the peer review process for medical literature has its challenges. It is a time-consuming process. It may be a challenge to find the time to read and critically assess submitted manuscripts. Patients may have competing priorities in their lives, including full- time jobs and time-demanding and energy-demanding treatments or treatments for their family members. There is a learning 
curve for anyone who is new to the peer review process and the conventions of academic publishing, although BMJHCI provides guides ${ }^{2}$ and support for new reviewers. Whereas researchers are writing and publishing as part of their jobs, we recognise this is extracurricular workload for programme participants. This has been recognised by major research funders like the National Institute for Health Research (NIHR) ${ }^{3}$ in the UK and the PatientCentered Outcomes Research Institute (PCORI) ${ }^{4}$ in the USA, who offer a level of reimbursement to patient and public representatives who participate in their research. We support this principle and are extending it to journal contributions.

People who are interested in participating can apply by filling out a short online form (available at https://bit. ly/BMJHCI-PPI-application) sharing their background and relevant experiences. They will indicate whether they would like to serve as an author (writing articles), or as a reviewer (reviewing articles), or both. Once submitted, members of the BMJHCI oversight panel will review the applications and select a diverse mix of participants for the BMJHCI partnership programme. For individuals in countries that are unable to access the form, contact info.bmjhci@bmj.com to express interest in participating in the partnership programme.

\section{WHAT PEOPLE WILL DO: WRITING}

Patient-written articles are one form of patient involvement in research. A patient-written article is a research article that is written by patients or caregivers about their own experiences with a disease or condition, or of others in their community, from the perspective of how information, communication and digital technology have made things better or worse. For example, a patient who receives lab results via their online health portal regarding a new diagnosis may discuss the benefits and challenges of receiving this information digitally and how that impacts their care or perception of care. The articles will also be peer-reviewed by patients or caregivers.

Patient-written articles have several benefits. They allow patients to share their specific, personal experiences with the disease or condition and the process of accessing or receiving healthcare. Patient-written articles are also likely to be of high quality, as patients who write the articles are intimately familiar with the disease or condition and the challenges it presents, and are likely to cover topics and perspectives that are not currently found in existing medical literature. Some of the patient perspectives regarding informatics, particularly around accessing or receiving information, are often not well known to clinicians and others working to design such systems in healthcare. As such, patient-written articles provide an opportunity to improve the understanding of the lived experience of the disease or condition-including interactions and communications with the healthcare system itself. Patient-written articles can also contribute to a shared language and understanding of health and care topics that is more accessible to a wider audience.

\section{WHAT PEOPLE WILL DO: REVIEWING}

In addition to patients and carers contributing to research in other ways, they may also choose to serve as patient (peer) reviewers. This is a role that has traditionally been performed only by academic researchers.

There are many benefits to having patient reviewers, such as providing clarity to the authors by asking more detailed questions about design, methods and analyses. Patient reviewers can provide insight into the language of a manuscript that can be unintentionally written in a jargon-filled way that may not be understandable to patients or other researchers. This again reflects the common requirement of research funders for a 'plain language' (if that is the vernacular) or 'lay' summary in a grant application. Readability assessment methods such as the Gunning Fog Index ${ }^{5}$ can get you so far, but actual patient or carer review can often take you a lot further in simplifying your writing. Moreover, patient reviewers can aid researchers and other authors to have a better understanding of patient perspectives and shape future research involving patients. Patient reviewers can provide valuable feedback about the article itself as well as the direction of future research more thoroughly and appropriately involving patient perspectives.

\section{WHY THIS MATTERS}

Journals such as the BMJ have previously had patient and carer panels, who have contributed patient-written articles, but not all journals have the resources or ability to pay patients and carers to be involved at this level of authorship and peer review for medical literature. We think patients and carers should be funded to participate at this stage of research as well as other stages of research. Peer review is often viewed as the gold standard for assessing the quality of research. The quality of peer review can be greatly improved by recruiting patients to peer review and improve readability and understanding of medical literature and to ensure that research and other articles appropriately include what matters most to patients.

Other journals should consider adopting a similar approach in order to involve patients in research, and to create a more collaborative relationship between the research community and patients. It may be particularly useful for journals that publish articles about diseases and conditions which are not yet well understood by the general population, and so the voice of the patient is perhaps more important than what we may currently see represented in the existing medical literature. Healthcare and medical literature may historically be perceived as one sided, as journals are typically written by and for individuals delivering care. But increasingly, patients are accessing and using medical literature themselves as well, 
due to lack of credible information elsewhere online. Just as real-time communication is two-way communication, both healthcare providers and patients should have a voice in medical literature, and involving patients in journals is an important step toward amplifying and supporting the balance of perspectives.

\section{CONCLUSION}

Patients are the whole purpose of research and practice in health and care, so this rightly includes their role in the publication and review of health informatics literature as well as the publication of their own perspectives regarding access and delivery of healthcare. Patients and carers can provide valuable insights into research articles, and they can also serve as effective peer reviewers. The BMJHCI is excited to kick off the new partnership programme and encourages all interested patients and carers to apply to participate as authors and/or reviewers.

\section{Twitter Dana Lewis@DanaMLewis}

Contributors DL and PS co-wrote and equally contributed to the development of this manuscript.

Funding The authors have not declared a specific grant for this research from any funding agency in the public, commercial or not-for-profit sectors.
Competing interests None declared.

Patient consent for publication Not required.

Provenance and peer review Commissioned; internally peer reviewed.

Open access This is an open access article distributed in accordance with the Creative Commons Attribution Non Commercial (CC BY-NC 4.0) license, which permits others to distribute, remix, adapt, build upon this work non-commercially, and license their derivative works on different terms, provided the original work is properly cited, appropriate credit is given, any changes made indicated, and the use is non-commercial. See: http://creativecommons.org/licenses/by-nc/4.0/.

\section{ORCID iDs}

Dana Lewis http://orcid.org/0000-0001-9176-6308

Philip Scott http://orcid.org/0000-0002-6289-4260

\section{REFERENCES}

1 BMJ Health \& Care Informatics: Patient and Public Involvement. Available: https://informatics.bmj.com/pages/patient-and-publicinvolvement/ [Accessed 9 Nov 2021].

2 Salmi L, Blease C. A step-by-step guide to peer review: a template for patients and novice reviewers. BMJ Health Care Inform 2021;28:e100392.

3 Payment guidance for researchers and professionals. Available: https://www.nihr.ac.uk/documents/payment-guidance-forresearchers-and-professionals/27392 [Accessed 27 Aug 2021].

4 PCORI compensation framework for engaged research partners. Available: https://www.pcori.org/sites/default/files/PCORICompensation-Framework-for-Engaged-Research-Partners.pdf [Accessed 27 Aug 2021].

5 Gunning fog index. Available: http://gunning-fog-index.com/ [Accessed 7 Sept 2021]. 